\title{
ACESSIBILIDADE E INCLUSÃO SOCIAL DE IDOSOS DEPENDENTES SOB O OLHAR DO CUIDADOR FAMILIAR
}

\author{
Thaís Botelho da Silva \\ Jorge Luiz de Andrade Trindade ${ }^{2}$ \\ Simone Glimm³
}

resumo

Esta pesquisa compreende um estudo observacional descritivo de abordagem qualitativa. Seu principal objetivo é descrever a acessibilidade e a inclusão social de idosos dependentes de uma comunidade de Porto Alegre, RS, a partir da visão de seus cuidadores familiares. Por meio do mapeamento de usuários de uma Unidade de Saúde da Família, foram identificados sete idosos com alterações neurofuncionais e seus cuidadores responderam a três instrumentos: questionário com questões demográficas e socioeconômicas; Medida de Independência Funcional (MIF); e uma entrevista semiestruturada baseada no modelo biopsicossocial de incapacidade. Foi feita a análise de conteúdo das entrevistas e do discurso organizado nas

1 Graduada em Fisioterapia. Mestra em Saúde Coletiva. Fisioterapeuta da Secretaria Estadual da Saúde do Rio Grande do Sul. E-mail: thaisbs.fisio@gmail.com.

2 Graduado em Fisioterapia. Mestre em Saúde Coletiva. Professor Adjunto da Universidade Feevale. E-mail: jorge.trindade@gmail.com.

3 Graduada em Serviço Social. Tutora da Residência Integrada em Saúde da Escola de Saúde Pública ESP-RS/SES. E-mail: sglimm@ig.com.br. 
seguintes categorias: sair de casa, transporte, ambiente público e doméstico, relações sociais e direitos. Os resultados apontaram que os cuidadores familiares eram do sexo feminino, com idade entre 18 e 66 anos e que os idosos possuíam faixa de renda abaixo da média regional. Quanto à funcionalidade, a maioria não apresentou grau de dependência funcional muito elevado, necessitando de médio auxílio nas atividades avaliadas. Os dados mostraram a dificuldade de acesso e a presença de barreiras arquitetônicas e de comunicação, como o preconceito e a discriminação. É necessário, portanto, que medidas sejam tomadas pelo Estado e pela sociedade para que assumam o compromisso de incluir todos os cidadãos, independentemente de suas características individuais.

palavras-chave

Saúde do idoso. Cuidadores. Estruturas de acesso.

\section{Introdução}

O envelhecimento é um fenômeno observado no mundo todo. Estimativas indicam que no ano de 2050 existam cerca de dois bilhões de pessoas idosas (com 60 anos ou mais) no mundo, concentrando-se principalmente em países em desenvolvimento, como no Brasil. No Rio Grande do Sul, a população de idosos atinge $13,7 \%$ da população total, sendo um dos estados com maior expectativa de vida ao nascer (IBGE, 2010; BRASIL, 2006).

De acordo com Floriano et al. (2012), a condição de ser idoso pode levar a diversas alterações de saúde que decorrem do declínio fisiológico da capacidade funcional e do aparecimento de agravos crônicos não transmissíveis. Disso resulta uma maior carga de doenças na população, maior prevalência de incapacidades e aumento do uso dos serviços de saúde. Nessa situação, o idoso pode tornar-se frágil e dependente de pessoas ou de equipamentos específicos para a realização de tarefas essenciais à sobrevivência no dia a dia (VERAS, 2009).

Esta é uma questão essencialmente importante em contextos de acentuada desigualdade social, haja vista que os esforços institucionais têm sido pontuais e desarticulados, recaindo sobre a família a maior responsabilidade do cuidado de idosos dependentes. Assim, torna-se premente a aplicação de uma política pública de apoio às famílias e práticas de saúde que possibilitem 
um suporte qualificado e constante, de forma que a família possa ter condições reais de prestar o cuidado, de acordo com as necessidades apresentadas em cada situação (AMARAL et al., 2012; FLORIANO et al., 2012; VERAS, 2009).

A acessibilidade tem sido abordada em diversos segmentos e, recentemente, vem ganhando espaço em discussões na área da saúde. De acordo com o Ministério da Saúde (BRASIL, 2010), é pela acessibilidade que se permite ganhos de autonomia e mobilidade para que todas as pessoas possam desfrutar dos espaços com mais segurança, confiança e comodidade. Transcende a questão das barreiras arquitetônicas, pois se refere a qualquer restrição à participação plena provocada pelas barreiras sociais. A legislação que abrange o tema contempla de certa forma, aspectos sobre saúde, educação, locomoção, transporte, trabalho e lazer, e promove a acessibilidade como um meio capaz de viabilizar a inclusão social (DINIZ; BARBOSA; SANTOS, 2009; GIRONDI; SANTOS, 2011).

Algumas pesquisas (AMARAL et al., 2012; GIRONDI; SANTOS, 2011; SIQUEIRA et al., 2009) têm abordado o cotidiano de idosos com dependência, lançando olhar sobre o acesso a determinados serviços de saúde. No entanto, foi diante das percepções de territorialização e através do contato direto com os idosos restritos ao domicílio que se conduziu uma reflexão sobre o quanto as condições de acesso têm influenciado a inclusão social destes indivíduos. Fez-se necessário um estudo para descrever a realidade dessa população, problematizando a acessibilidade num sentido amplo, que levasse em consideração não só os aspectos relacionados ao sistema de saúde ou à lesão, mas, principalmente, as interações entre estes fatores e as singularidades do contexto social. Desta forma, o objetivo deste estudo foi descrever a acessibilidade e a inclusão social de idosos dependentes de uma comunidade de Porto Alegre-RS.

\section{Metodologia}

Esta pesquisa compreendeu um estudo observacional descritivo de abordagem qualitativa, realizada a partir do mapeamento de usuários que recebiam atenção domiciliar de uma Unidade de Saúde da Família, na cidade de Porto Alegre, RS. Mediante registros dos usuários do sistema de saúde local, foram identificados 34 (trinta e quatro) pessoas, com os mais diversos comprometimentos e com diferentes etiologias incapacitantes. Destes, foram selecionados indivíduos com 60 anos ou mais, com comprometimento neurofuncional, restritos ao domicílio e que possuíssem cuidadores familiares. Assim, a população em estudo foi definida pela totalidade de cuidadores de 
idosos restritos ao domicilio, encontrados nessas condições na comunidade, totalizando sete cuidadores.

Sabendo da importância que tem o cuidador para o sucesso da adesão à atenção domiciliar, sendo este o principal elo com a equipe de saúde e aquele que mais convive com o idoso, decidiu-se por ele ser o informante e entrevistado do estudo. Permite-se, dessa forma, abordar inclusive a realidade dos usuários idosos que tivessem alguma alteração cognitiva que impedisse a condução da coleta de dados verbais, destacando então a perspectiva do cuidador familiar.

Os participantes assinaram o Termo de Consentimento Livre e Esclarecido (TCLE), conforme resolução 466/12 do Conselho Nacional de Saúde. A pesquisa foi aprovada pelo Comitê de Ética e Pesquisa da Secretaria Municipal de Saúde de Porto Alegre, sob o no 001.053403.10.0.

\subsection{Procedimento de geração de dados}

A geração dos dados aconteceu por meio de visita domiciliar, conduzida por uma conversa informal com o cuidador e composta por três instrumentos: questionário de caracterização do cuidador, Medida de Independência Funcional (MIF) dos idosos e entrevista semiestruturada.

Na primeira parte, um questionário abrangeu questões sobre o perfil do cuidador em estudo, trazendo algumas características demográficas e socioeconômicas. A seguir, foi realizada avaliação do nível de dependência a partir de inquérito com o cuidador sobre a capacidade do idoso de realizar determinadas tarefas básicas da vida diária. Utilizou-se a MIF, um questionário composto de 18 atividades, entre elas autocuidado, locomoção, controle esfincteriano, transferências, comunicação e cognição social. Neste instrumento, a avaliação do desempenho varia numa escala de 1 a 7, de acordo com o nível de dependência (RIBERTO et al., 2004; RICCI; KUBOTA; CORDEIRO, 2005). Desta forma, perguntas diretas eram dirigidas ao cuidador e a pesquisadora assinalava a ficha de coleta conforme as informações fornecidas.

Também foi realizada uma entrevista semiestruturada, que foi gravada e fielmente transcrita, abordando dois temas principais: acessibilidade e inclusão social. Tais temas foram desenvolvidos ao longo de dez perguntas, possibilitando que o entrevistado discorresse sobre o assunto sem se prender à indagação. As questões foram baseadas no modelo biopsicossocial de incapacidade, preconizado pela Classificação Internacional de Funcionalidade - CIF (OMS, 2002). 


\section{Características das cuidadoras e idosos}

Sobre o perfil das informantes deste estudo, pode-se afirmar que todas eram do sexo feminino, com idades entre 18 e 66 anos. A ocorrência do grau de parentesco foi de três esposas, duas noras, uma filha e uma neta. Esses dados estão de acordo com a pesquisa intitulada "Estudo do Suporte Domiciliar aos Adultos com Perda de Independência e Perfil do Cuidador Principal", no qual 92,9\% dos cuidadores eram mulheres, sendo também um dado presente na maioria dos estudos envolvendo cuidadores (KARSCH, 1998 apud KARSCH 2003).

Quanto ao nível de escolaridade, apenas duas participantes chegaram ao ensino médio. Quatro delas não possuem ensino fundamental completo, sendo que uma nunca frequentou uma escola regular, porém foi ensinada a ler, escrever e fazer operações básicas. Vale destacar que a baixa escolaridade pode ser um fator complicador, visto que muitas das tarefas desempenhadas no cuidado podem exigir habilidades complexas como interpretar receitas e administrar medicação, assim como seguir orientações sobre dietas e curativos (CARTAXO et al., 2012).

A maioria dos idosos da pesquisa possuía rendimento per capita igual ou inferior a meio salário mínimo mensal. Boa parte da fonte de renda familiar ou advinha de recursos de aposentaria do idoso ou do Benefício de Prestação Continuada (BPC). De acordo com a última Pesquisa Nacional de Amostra por Domicílios, apenas 5,1\% da população idosa da região metropolitana de Porto Alegre vive com até meio salário mínimo per capita (IBGE, 2010). Esse resultado mostra que os idosos deste estudo pertencem a uma parcela da sociedade que vive aquém das características médias regionais e, possivelmente, com dificuldade para adquirir insumos para seu sustento básico. Nesse sentido, Lima-Costa et al. (2003) e Caldas (2003) há quase 15 anos já haviam relacionado a situação socioeconômica dos idosos à saúde e à qualidade de vida, trazendo a hipótese que idosos nestas condições tendem a ter um óbito precoce.

Com o resultado do MIF, um idoso pode ser classificado ${ }^{4}$ com independência modificada (escore 109) e seis com dependência modificada (escores 95, $89,82,59,55,21$ ), sendo que três deles requerem assistência para até $25 \%$ das atividades e três requerem para $50 \%$ das atividades. Apenas um dos indivíduos apresenta dependência próxima da completa (escore 21), os demais, mesmo

4 Escores decrescentes de acordo com Ricci, Kubota e Cordeiro (2005): 126-104: Independência Completa/Modificada; 103-61: Dependência Modificada (assistência para até 25\% da tarefa); 60-19: Dependência Modificada (assistência para até 50\% da tarefa); 18: Dependência completa. 
tendo dependência para até $50 \%$ das tarefas, não possuem escores tão baixos. Assim, é possível perceber que uma boa parte dos indivíduos classificados como restritos ao domicílio, não possui um grau de dependência funcional muito elevado, necessitando de médio auxílio nas atividades avaliadas. Este achado já pode oferecer pistas sobre quais seriam as principais barreiras e o que verdadeiramente os coloca em situação de incapacidade e os priva/dificulta de sair do domicílio.

\subsection{Entrevistas}

Para análise do conteúdo das entrevistas, conforme orientam Minayo (2007) e Oliveira (2007), as transcrições foram primeiramente divididas em três grandes categorias teóricas, que são: acessibilidade, inclusão social e dependência. A partir da pesquisa de campo, os dados foram subdivididos em categorias empíricas, baseando-se nos questionamentos realizados e no conteúdo dos discursos. As categorias empíricas foram: sair de casa, transporte, ambiente doméstico, ambiente público, direitos e relações sociais.

A seguir, as respostas similares ou convergentes definiram as unidades de análise, que foram discutidas com a literatura de referência e o contexto sociocultural presente. A fim de preservar a identidade das colaboradoras, foram-lhes emprestados nomes de pedras preciosas: Ônix, Esmeralda, Topázio, Quartzo, Ametista, Diamante, Rubi.

\subsubsection{Sair de casa}

Pacientes domiciliares são assim definidos pelo DeCS (BIREME, 2017) como sendo aqueles impossibilitados de deixar sua casa sem esforço excepcional e apoio, que são providos ou têm necessidade de serviços de saúde em casa, incluindo tratamento médico e cuidado pessoal.

$\mathrm{Na}$ realidade dos entrevistados, os momentos citados para ausentar-se de casa foram para realizar atividades como ir à igreja, buscar atendimento de saúde, visitar parentes, resolver assuntos bancários e relativos à previdência. Aparecem nas falas em média dois destinos que compõem o cotidiano de cada idoso. No discurso a seguir, é possível ver quais as situações em que o usuário sai de casa e observa-se uma frequência um tanto restrita: 
Para Cohen e Duarte (2004), a impossibilidade de vivenciar adequadamente os espaços faz com que muitas pessoas com dificuldade de locomoção não saiam de suas casas e percam o contato com o mundo externo. Os deslocamentos na cidade são organizados em função do fator tempo e das possibilidades oferecidas pelo espaço. Tais possibilidades, em muitos casos, são ínfimas e precárias, em função da acessibilidade dos locais e das condições que o idoso tem para se ausentar do domicílio.

\subsubsection{Transporte}

O meio de transporte é uma forma de operacionalizar o direito de ir e vir, previsto na Constituição Federal (BRASIL, 1988). A liberdade dos indivíduos perpassa por este aspecto tão fundamental para a consolidação da acessibilidade; em análise, nenhum dos entrevistados refere que usa o ônibus como meio de transporte.

Ainda que os idosos da pesquisa não sejam totalmente dependentes e que todos eles possuam cadeira de rodas, é consenso que o transporte coletivo não é um meio de transporte adequado e que ofereça boas condições. O carro, meio de transporte mais utilizado, nunca é de propriedade do núcleo familiar, às vezes sendo necessário o uso de serviços privados, como o táxi:

Pra ir no médico a gente pega o táxi, daí meu filho e eu pegamos ela e seguramos ela. (ESMERALDA, 49 anos).

No caso é só o carro do meu genro [...] Não! Ônibus não dá né, a gente não consegue. (TOPÁZIO, 64 anos).

Em estudo semelhante, de Amaral et al. (2012), que se propôs a analisar os fatores que dificultavam o acesso de idosos com alguma deficiência ou mobilidade reduzida aos serviços de saúde, observou-se que a ausência de transporte era a principal barreira arquitetônica. Entre os obstáculos que podem impedir o direito ao transporte, pode-se incluir o fato de que o local onde é possível embarcar no ônibus nem sempre é perto da residência e de fácil acesso. Outras situações são as condições do coletivo, se são adaptados adequadamente ou não, a frequência com que eles trafegam e a falta de preparo daqueles que conduzem o transporte. 
No que diz respeito às transferências, a importância do peso corporal foi um aspecto também lembrado pelas entrevistadas, já que muitas vezes foi necessário carregar o idoso e isso dificultava o deslocamento. Esse fator predispõe a dependência de terceiros, às vezes de pessoas fora do círculo familiar e que podem requerer, inclusive, subsídios financeiros:

Ah, eu acho horrível porque ele é muito gordo. O médico mesmo disse que ele tem que emagrecer um pouco [...] Ah, a dificuldade é que tem que pegar ele no colo. Tem que ter duas pessoas porque eu não consigo. Então ele tem que pagar um menino pra ajudar o meu pra levantar ele, pegar ele no colo, porque ele não consegue caminhar, não anda. Pulando nas pedras fica ruim, né. (ÔNIX, 66 anos).

\subsubsection{Ambiente público}

Conhecer as condições do ambiente público por onde os idosos transitam diz muito sobre o acesso que eles têm aos diversos locais. A existência de barreiras, obstáculos ou entraves que limitem ou impeçam o acesso prejudica a liberdade de movimento e a circulação com segurança. De acordo com a Lei 10.098/00 (BRASIL, 2000), essas barreiras podem ser classificadas em: arquitetônicas (urbanísticas, de edificação e nos transportes) e de comunicação.

Muito do acesso público refere-se às barreiras arquitetônicas e às características encontradas no próprio território, como ruas de difícil tráfego, seja de pedestres ou de automóveis, presença de declives e aclives acentuados, assim como diversos locais com terreno irregular:

Olha, tem lugares aí que não tem asfalto e que tá péssimo. [...] Pra uma pessoa de cadeira de rodas ali é difícil. Tem ruas aí que falta asfalto... que é muito horrivel, tem que tá catando os cantinhos pra andar porque é mais buraco do que rua plana. (RUBI, 61 anos).

Eu não acho que tá muito bom, não. Ainda têm pedras, coisas assim, ruas estreitas [...]. É que não dá pra passar com cadeira. As vezes não passa nem um carro, entendeu? Daí já é ruim, entendeu? (DIAMANTE, 18 anos).

Outro ponto a se destacar é a presença de barreiras de comunicação, como o preconceito, a discriminação, o sentimento de a deficiência ser algo contagioso e de grande estigma para a sociedade. Estas vivências foram relatadas pela cuidadora na fala a seguir: 
Uma droga né, porque se tu sai com uma pessoa com o quadro dela, as pessoas se afastam achando que tu tá levando um vírus muito contagioso. Até porque, velho ninguém gosta mais, é difícil. Aí tu começa a sentir o clima, né. Eles acham assim: se é deficiente por que não ficou em casa? Eu já ouvi isso. Eu sei por que eu saía com a minha mãe. Claro, sei que lugar de aleijado é em casa. É muito constrangedor tu ir num lugar público com uma pessoa deficiente. (AMETISTA, 54 anos).

Percebe-se que esta fala está marcada por concepções e práticas socialmente construídas sob o entendimento do deficiente como defeituoso, ou aberração. Essas e tantas outras denominações eram comuns até a década de 80 , fruto da cultura da normalidade, presente de diversas formas até os tempos contemporâneos (DINIZ; BARBOSA; SANTOS, 2009; GIRONDI; SANTOS, 2011).

Othero e Ayres (2012) ressaltam que estes sentidos e significados evocados relacionam a deficiência como o encontro com o que é diferente, com o outro. Desta forma, palavras como trauma, vergonha, medo e decepção permeiam o contexto daqueles que vivem em uma sociedade pouco sensível às variações nas habilidades corporais.

\subsubsection{Ambiente doméstico}

A casa é o local onde os idosos em estudo passam a maior parte do tempo. Analisar este ambiente torna-se fundamental para entender quais são as implicações possíveis na produção de saúde frente às limitações apresentadas. As barreiras arquitetônicas aqui encontradas classificam-se como entraves na edificação. Elas relacionam-se a duas áreas principalmente, que é o tamanho da casa e mais especificamente dos cômodos, e no que se refere às calçadas ou espaços que dão acesso ao ambiente público:

Como ali, né? A gente não pode sair com a cadeira até a rua porque não passa ali no bequinho, na rua, no portãozinho. Claro que dá pra arrumar o portão também. Essa parte que atrapalha. Aqui dentro no caso já não passa, mas no caso arredando a cama passa. É, dá um jeitinho... A casa não é tão espaçosa assim. E a casa lá em cima nem tem como subir. (QUARTZO, 43 anos).

Em outro estudo mais antigo (ANDERSON, 1997 apud CALDAS, 2003), também já havia sido evidenciado que em grandes centros urbanos os idosos vivem em domicílios com poucos cômodos e que estes possuem um tamanho cada vez menor, o que dificulta não só a privacidade do idoso, como também acaba se tornando um entrave para a qualidade de vida. 
Em alguns momentos, as condições intrínsecas dos idosos são elencadas como o grande fator incapacitante. E isso difere de caso a caso. Em algumas situações, a condição física é o que mais traz impedimentos. Em outras, a questão psicológica e motivacional é um fator determinante, como se pode ver na fala a seguir.

Eu acho que até a ponta da área dava pra ele ir se ele tivesse boa vontade, mas ele tem pouca boa vontade, então ele não vai. Eu não sei se ele tem medo de cair, se machucar e ele não vai. Ele não passa pro lado de fora da porta, ele não vai. (ÔNIX, 66 anos).

Conforme a Organização Mundial de Saúde (2002), a incapacidade é um fenômeno complexo, pois o estado de saúde da pessoa interage continuamente com o contexto social no qual ela vive. Nesse sentido, é importante levar em consideração esses dois fatores a fim de fazer uma melhor análise da situação, de modo a ampliar as capacidades e permitir maior independência. Compreender a vivência de uma pessoa com limitações físicas em determinado contexto e como esta percebe sua saúde e suas motivações são estratégias essenciais para favorecer o cuidado e oferecer apoio de acordo com as necessidades elencadas (GIRONDI; SANTOS, 2011).

\section{2 .5 Relações sociais}

As relações sociais que são estabelecidas dizem muito acerca da inclusão social. Uma sociedade inclusiva prevê a construção e o fortalecimento da cidadania pelo relacionamento entre os indivíduos diferentes entre si. Nesse sentido, quanto maior a convivência, sem discriminações, maior a inclusão (BRASIL, 2010). Idosos dependentes compõem parte da população de pessoas com deficiência e, igualmente, necessitam desfrutar do acesso ao espaço comum da vida em sociedade.

A inclusão social pode ser entendida como um processo que envolve ações mútuas entre a sociedade e a pessoa com deficiência, a fim de que os mais diversos indivíduos possam assumir seu papel social. Nesse sentido, o desenvolvimento da autonomia pode possibilitar a ampliação das relações sociais, principalmente para além do domínio familiar. Dentre os discursos analisados, é possível observar relatos de integração dos idosos com parentes e amigos e, também, relatos de dificuldades nos relacionamentos interpessoais: 
Ela se dava com todo mundo, mas ninguém vem ver ela. Ela tinha um monte de companheiros pra beber com ela, quando ela bebia, quando ela era mais nova. Porque depois que a pessoa fica doente, mais tarde... Un, cadê os amigos? Sumiram! (ESMERALDA, 39 anos).

Quando questionado sobre a inclusão social dos familiares, uma parte das entrevistadas disse que os idosos não tinham motivos para se sentirem excluídos em função da presença da família. Por outro lado, algumas disseram que, quando os idosos eram "saudáveis", eles estavam rodeados de pessoas e, que a condição atual, de certa forma, tem sido uma manifestação de exclusão. Esse achado se assemelha com a proposição de ciclo de invisibilidade, introduzida por Werneck (2005) nos estudos sobre deficiência no Brasil. Ela estabelece que o confinamento dentro de casa faz com que estas pessoas não sejam vistas pela comunidade e, desta forma, suas necessidades (acesso a bens, direitos e serviços) não são reconhecidas. Assim, a lógica do invisível se reproduz e só produz ainda mais exclusão.

Também se interrogou sobre a opinião das participantes sobre os idosos dependentes e os deficientes em geral. Em um dos discursos, quando perguntado se algum cadeirante, vítima de lesão medular, sem comprometimentos cognitivos, poderia ter uma vida normal, a resposta foi a seguinte:

Se a pessoa fala, se a pessoa entende tudo e só não consegue caminhar, eu acho que dá. Só não pode trabalhar, né. (QUARTZO, 43 anos).

No discurso acima, observa-se uma concepção de deficiência em uma relação estreita com a incapacidade. Desta vez, as percepções referem-se à inclusão no mercado de trabalho. Parte desta atitude pode ser explicada porque o deficiente tem sido visto como um sujeito doente e, por isso, incapaz de realizar e participar de certas atividades como o trabalho, que representa também sua função social dentro da sociedade atual (DINIZ; BARBOSA; SANTOS, 2009).

\section{Direitos}

As leis que regem nosso país norteiam a estruturação de políticas públicas. A legislação imbricada no tema do estudo envolve, primariamente, a Declaração Universal dos Direitos Humanos da Organização das Nações Unidas (1948). A partir dela, temas mais focados como o da pessoa com deficiência e da população idosa orientam nossas discussões.

No decorrer da entrevista, ao perguntar se os familiares teriam alguns direitos específicos ou preferências, a maioria apontou não saber da existência 
de prioridades em relação a outras pessoas. A minoria, porém, citou alguns direitos relacionados a transporte, acessibilidade e saúde:

Eu sei que os deficientes têm muitas prioridades nas calçadas, nos ônibus e isso tudo eu sei. Quanto ao idoso a única coisa que eu sei é que o idoso não fica na fila. Idoso tem prioridade de atendimento. (RUBI, 61 anos).

Importante ressaltar que, de acordo com o Estatuto do Idoso, é função do Estado garantir à pessoa idosa políticas públicas que permitam um envelhecimento saudável e em condições de dignidade (BRASIL, 2003). A política de saúde necessita de uma abordagem que reconheça o direito dos idosos à igualdade de oportunidades e de tratamento em todos os aspectos da vida. Frente a isso, orientar e esclarecer sobre direitos sociais também pode ser uma ação dentre as práticas para construção da cidadania (BRASIL, 2006). Aparece também de forma muito clara nas falas o direito à saúde. Esse fato pode ser explicado porque, na condição da pesquisa, a entrevistadora era uma profissional de saúde e, naquele instante, também representava a unidade de saúde de referência da região:

Quantos médicos têm no posto? Levanta os idosos de toda essa vila aquil... Não tem condições! E quantos idosos tem pra ir nas casas? Faz as continhas... Tu é o médico e tem meia hora pra fazer tudo isso. Dá tempo? Não dá! (AMETISTA, 54 anos).

A única coisa que eu acho que ela ia ter direito é fazer uma fisioterapia em casa, mas de vez em quando, né. Se ela fizesse uma fisioterapia adequada pra ela, assim, nem que fosse dois dias por semana, eu acharia que ela estaria caminhando já. (DIAMANTE, 18 anos).

Os trechos acima apontam para a insuficiência de cuidados ofertados pelo serviço de saúde, principalmente no que tange à atenção domiciliar e à reabilitação. Cabe à Atenção Básica a gestão do cuidado de toda pessoa de seu território. Nos casos em que o idoso possui dificuldade de locomoção e/ ou impossibilidades para ir até a unidade de saúde, o cuidado poderá ser ofertado no próprio domicílio, com equipes que se organizarão de acordo com a complexidade que cada situação envolve. A atenção domiciliar deve estar articulada e integrada aos demais componentes da rede de atenção e agrega ações de promoção à saúde, prevenção de agravos, tratamento de doenças e, ainda, medidas de reabilitação (BRASIL, 2012). No entanto, o cotidiano da assistência tem mostrado que mesmo que existam avanços na legislação e políticas públicas direcionadas ao tema, as ações de reabilitação e de atenção 
à saúde no domicílio ainda são incipientes e não estão ao alcance de todos que as necessitam (AMARAL et al., 2012; GIRONDI; SANTOS, 2011).

O tema abordado no estudo é amplo, complexo e envolve uma série de questões do cotidiano da população idosa e dependente. O aumento do número de idosos brasileiros é um fato ascendente, mas ainda causa estranhamento para diversos segmentos da sociedade. Por sua vez, a população de deficientes sofre um estigma social de longa data. Iniciativas têm sido tomadas em algumas frentes, porém ainda são insuficientes diante da construção histórica e social e do contingente de pessoas sob estas condições.

Foi possível identificar e descrever diversas dificuldades não só no ambiente público como no doméstico. Sob este aspecto, é necessário lembrar que para a acessibilidade ser efetivada é imprescindível uma mudança nas barreiras arquitetônicas e estruturais, mas principalmente uma mudança de atitude frente ao problema. O preconceito ainda é muito presente e apareceu muitas vezes imbricado em todas as categorias.

A inclusão deve acontecer em todas as esferas da vida social. Para tanto, o exercício da intersetorialidade é um caminho a percorrer, contando com medidas articuladas na saúde, habitação, assistência social e no trabalho. A sociedade e o Estado possuem o compromisso de incluir todos os cidadãos, independentemente de suas diferenças individuais, fornecendo-lhes oportunidades igualitárias com o intuito de diminuir as discrepâncias sociais.

Ainda há muito que se discutir e é necessário construir novos olhares acerca da população idosa e dependente, e desconstruir tudo aquilo que afasta estas pessoas de experienciar condições plenas de participação na vida comunitária. Estudos que problematizem as condições de acesso e sua interferência na inclusão social devem ser mais explorados para que haja uma maior reflexão sobre a temática e que possam servir de instrumentos para a promoção da cidadania, em uma realidade aonde os direitos sejam acessados e garantidos não apenas por uma parcela minoritária da população. 
abstract

This work comprises a descriptive observational study with qualitative approach. Its main aim is to describe the accessibility and social inclusion of dependent elderly at a neighborhood of Porto Alegre, from the perspective of their family caregivers. From the mapping of users of a Family Health Unit, seven elderly people with neurofunctional disorders were identified, and their caregivers responded to three instruments: demographic and socioeconomic issues survey, Functional Independence Measure (FIM) and a semi-structured interview based on the biopsychosocial model of disability. A content analysis was performed and the speech was organized into the following categories: leaving home, transportation, public and domestic environment, social relationship and rights. The results indicated that caregivers were female aged between 18 and 66 years, and the elderly per capita income was below the regional average. Regarding functionality, the majority did not show a high degree of functional dependence, requiring medium assistance in the activities evaluated. The data showed the difficulty of access and the presence of architectural and communication barriers, such as prejudice and discrimination. Therefore, it is necessary that measures be taken by the State and society to make a commitment to inclusion of all citizens, regardless of their individual characteristics.

keywords

Elderly health. Caregivers. Architectural accessibility.

referências

AMARAL, Fabienne Louise Juvêncio dos Santos et al. Fatores associados com a dificuldade no acesso de idosos com deficiência aos serviços de saúde. Ciência \& Saúde Coletiva, Rio de Janeiro, v. 17, n. 11, p. 2991-3001, nov. 2012.

BRASIL. Ministério da Saúde. Secretaria de Atenção à Saúde. Departamento de Atenção Básica. Caderno de Atenção Domiciliar. Brasília, DF: Ministério da Saúde, 2012. Disponível em: <http://189.28.128.100/dab/docs/publicacoes/geral/cad_vol1. pdf>. Acesso em: 10 abr. 2017.

Secretaria de Atenção à Saúde. Departamento de Ações Programáticas Estratégicas. Atenção à saúde da pessoa com deficiência no Sistema Único de 
Saúde - SUS. 1 ed. 1 reimp. Brasília, DF: Ministério da Saúde, 2010. Disponível em: $<$ http://portal.saude.gov.br/portal/arquivos/pdf/atensaudecomdefic.pdf>. Acesso em: 21 nov. 2013.

Envelhecimento e saúde da pessoa idosa. Brasília: Ministério da Saúde, 2006. (Cadernos de Atenção Básica, 19) (Série A. Normas e Manuais Técnicos).

Lei $n^{\circ} 10.741$, de $1^{\circ}$ de outubro de 2003. Dispõe sobre o Estatuto do Idoso e dá outras providências. Diário Oficial [da] República Federativa do Brasil, Brasília, DF, 3 out. 2003. Disponível em: <http://www.planalto.gov.br/ccivil_03/LEIS/2003/L10.741. htm>. Acesso em: 10 abr. 2017.

Lei no 10.098, de 19 de dezembro de 2000. Estabelece normas gerais e critérios básicos para a promoção da acessibilidade das pessoas portadoras de deficiência ou com mobilidade reduzida, e dá outras providências. Diário Oficial [da] República Federativa do Brasil, Brasilia, DF, 20 dez. 2000. Disponível em: <http://www. planalto.gov.br/ccivil_03/Leis/L10098.htm>. Acesso em: 8 out. 2013.

Constituição Federal de 1988. Promulgada em 5 de outubro de 1988. Disponível em <http://www.planalto.gov.br/ccivil_03/constituicao/constituição.htm>. Acesso em: 21 nov. 2013

CALDAS, Célia Pereira. Envelhecimento com dependência: responsabilidades e demandas na família. Rio de Janeiro. Cadernos de Saúde Pública, v. 19, n. 3, p. 733-781, jun. 2003

CARTAXO, Hermília Gabrielly de Oliveira et al. Vivência dos cuidadores familiares de idosos dependentes: revelando estratégias para o enfrentamento do cotidiano. Estudos Interdisciplinares sobre o Envelhecimento, Porto Alegre, v. 17, n. 1, p. 59-74, jun. 2012

COHEN, Regina; DUARTE, Cristiane Rose. Ações inclusivas de sucesso. In: SEMlNÁRIO INTERNACIONAL SOCIEDADE INCLUSIVA, 3., 2004, Belo Horizonte. Anais... Belo Horizonte: PUC Minas, 2004. p. 1-14.

CENTRO LATINO-AMERICANO E DO CARIBE DE INFORMAÇÃO EM CIÊNCIAS DA SAÚDE (BIREME). Descritores em Ciências da Saúde: DeCS. ed. rev. e ampl. São Paulo: BIREME: OPAS: OMS, 2017. Disponível em: <http://decs.bvsalud.org>. Acesso em 22 de jun. 2017.

DINIZ, Débora; BARBOSA, Lívia; SANTOS, Wederson Rufino dos. Deficiência, direitos humanos e justiça. Sur: revista internacional de direitos humanos, São Paulo, v. 6, n. 11, p. 64-77, dez. 2009.

FLORIANO, Luciane Almeida et al. Cuidado realizado pelo cuidador familiar ao idoso dependente, em domicílio, no contexto da estratégia de Saúde da Família. Texto \& Contexto Enfermagem, Florianópolis, v. 21, n. 3, p. 543-548, set. 2012.

GIRONDI, Juliana Balbinot Reis; SANTOS, Silvia Maria Azevedo. Deficiência física em idosos e acessibilidade na atenção básica em saúde: revisão integrativa da literatura. Revista Gaúcha de Enfermagem, Porto Alegre, v. 32, n. 2, p. 378-384, jun. 2011.

INSTITUTO BRASILEIRO DE GEOGRAFIA E ESTATÍSTICA (IBGE). Sintese de indicadores sociais: uma análise das condições de vida da população brasileira. Rio de Janeiro: IBGE, 2010.

KARSCH, Úrsula Margarida Simon. Idosos dependentes: famílias e cuidadores. Cadernos de Saúde Pública, Rio de Janeiro, v. 19, n. 3, p. 861-866, maio/jun. 2003.

LIMA-COSTA, Maria Fernanda et al. Desigualdade social e saúde entre idosos brasileiros: um estudo baseado na Pesquisa Nacional por Amostra de Domicílios. Cadernos de Saúde Pública, Rio de Janeiro, v. 19, n. 3, p. 745-57, maio/jun. 2003.

MINAYO, Maria Cecília de Souza (Org.). Pesquisa social, teoria método e criatividade. Petrópolis: Vozes, 2007. 
Data de submissão: 21/08/2014

Data de aprovação: 19/05/2017

ORGANIZAÇÃO DAS NAÇÕES UNIDAS (ONU). Declaração Universal dos Direitos Humanos. Paris: ONU, 1948. Disponível em: <http://www.dudh.org.br/wp-content/ uploads/2014/12/dudh.pdf>. Acesso em: 19 dez. 2014.

ORGANIZAÇÃO MUNDIAL DE SAÚDE (OMS). Rumo a uma linguagem comum para funcionalidade, incapacidade e saúde: CIF. Genebra: OMS, 2002.

OTHERO, Marilia Bense; AYRES, José Ricardo de Carvalho Mesquita. Necessidades de saúde da pessoa com deficiência: a perspectiva dos sujeitos por meio de histórias de vida. Interface: comunicação, saúde, educação, Botucatu, v. 16, n. 40, p. 219-234, mar. 2012

RIBERTO, Marcelo et al. Validação da versão brasileira da Medida de Independência Funcional. Acta Fisiátrica, São Paulo, v. 11, n. 2, p. 543-548, jul./set. 2004.

RICCI, Natalia Aquaroni; KUBOTA, Maristela Tiemi; CORDEIRO, Renata Cereda. Concordância de observações sobre a capacidade funcional de idosos em assistência domiciliar. Revista de Saúde Pública, São Paulo, v. 39, n. 4, p. 655-662, ago. 2005.

SIQUEIRA, Fernando Carlos Vinholes et al. Barreiras arquitetônicas a idosos e portadores de deficiência física: um estudo epidemiológico da estrutura física das unidades básicas de saúde em sete estados do Brasil. Ciência \& Saúde Coletiva, Rio de Janeiro, v. 14, n. 1, p. 39-44, fev. 2009

VERAS, Renato. Envelhecimento populacional contemporâneo: demandas, desafios e inovações. Revista de Saúde Pública, São Paulo, v. 43, n. 3, p. 548-554, maio/jun. 2009.

WERNECK, Claudia. Manual sobre desenvolvimento inclusivo para midia e profissionais de comunicação. Rio de Janeiro: WVA, 2005. Disponível em: <http://www.escoladegente.org.br/publicacoes>. Acesso em: 10 abr. 2017. 